\title{
STUDI PENURUNAN TANAH GAMBUT PADA KONDISI SINGLE DRAIN DENGAN METODE VERTIKAL DRAIN DENGAN MENGGUNAKAN PRELOADING
}

\author{
Ahmad Herison, Yuda Romdania, Febrizky C Putri \\ Dosen Fakultas Teknik Universitas Lampung \\ Email : ahmadherison@yahoo.com
}

\begin{abstract}
ABSTRAK
Pembangunan konstruksi di atas tanah gambut akan mendapatkan beberapa masalah geoteknik. Salah satunya adalah terjadinya penurunan (konsolidasi) tanah yang apabila mengalami pembebanan diatasnya maka tekanan air pori akan naik sehingga air pori ke luar yang menyebabkan berkurangnya volume tanah, oleh karena itu akan terjadi penurunan pada tanah. Tujuan dari penelitian ini adalah untuk mengetahui dan membandingkan data hasil pengujian penurunan lapis tanah pada tanah gambut menggunakan metode sand drain dengan Pembebanan Bertahap pada kondisi Single Drain (Pola Segitiga dan Pola Segiempat). Pengujian dilakukan di Laboratorium Mekanika Tanah Universitas Lampung. Sampel tanah yang akan diteliti adalah tanah gambut pada kedalaman $20 \mathrm{~cm}$. Pelaksanaan pengujian dilakukan dalam 2 tahap. Pertama adalah pengujian sifat fisik dan konsolidasi tanah gambut. Kedua adalah pengujian lama waktu pengeringan pada tanah gambut akibat pengaruh metode drainase menggunakan bahan pasir. Data yang didapatkan dari percobaan diolah, dan kemudian hasil perhitungan tersebut ditabelkan dan dibuat grafik.

Dari penelitian ini didapatkan: Koefisien konsolidasi (Cv) untuk pola segitiga sebesar 0,00079 $\mathrm{cm} 2 /$ menit dan untuk pola segiempat sebesar 0,0028 cm2/menit, nilai indeks tekanan Cc untuk pola segitiga sebesar 2,5589 dan untuk pola segiempat sebesar 1,0041. Sehingga diambil kesimpulan : (1) Penggunaan metode sand drain dengan pola segiempat ternyata dapat menurunkan tanah lebih cepat daripada dengan pola segitiga (2) Nilai Cv (koefisien konsolidasi) sebelum pembebanan lebih besar daripada setelah pembebanan, sedangkan nilai Cc (indeks pemampatan) sesudah pembebanan lebih besar daripada sebelum pembebanan.
\end{abstract}

\section{Kata Kunci : Gambut, Single Drain, Konsolidasi}

\section{PENDAHULUAN}

Tanah gambut memiliki sifat dan karakteristik yang sangat berbeda dengan tanah lempung (Bowles, J. E. 1989).Struktur sebagian besar rekayasa yang di bangun dengan tanah dan respon antara tanah dan struktur disebut sebagai interaksi struktur teknik tanah. Tanah gambut dianggap tidak cocok untuk mendukung bangunan dalam perilaku alaminya memiliki kelembaban konten yang tinggi ( $>100 \%$ ), kompresibilitas tinggi $(0,9-1.5)$ dan memiliki kekuatan geser rendah ( 5-20 kpa ) (Razali, Siti. Bakar, I dan Zainorabidin, A. 2012). Pembangunan konstruksi di atas tanah gambut akan mendapatkan beberapa masalah Geoteknik. Salah satunya adalah terjadinya penurunan (konsolidasi) tanah yang apabila mengalami pembebanan diatasnya maka tekanan air pori akan naik sehingga air-pori ke luar yang menyebabkan berkurangnya volume tanah, oleh karena itu akan terjadi penurunan pada tanah. Penambahan beban di atas suatu permukaan tanah dapat menyebabkan lapisan tanah di bawahnya mengalami pemampatan. Pemampatan tersebut diakibatkan oleh adanya deformasi partikel tanah, relokasi partikel, keluarnya air atau udara dari dalam pori. (Zainorabidin, A and Bakar, I, 2003)

Salah satu metoda untuk mempercepat terjadinya proses konsolidasi untuk konstruksi dari beberapa struktur yaitu dengan menggunakan metoda Sand Drain. Aliran air arah horizontal akan di induksi oleh Sand Drain dan untuk aliran air arah vertikal di induksi menggunakan pasir diatasnya. Jarak drainase arah horizontal yang lebih pendek menambah kecepatan proses konsolidasi beberapa kali lebih cepat. 


\section{METODOLOGI PENELITIAN}

Tanah yang diuji adalah jenis tanah gambut yang diambil dari Desa Rawa Sragi, Kabupaten Lampung Timur. Sampel tanah yang diteliti adalah tanah gambut pada kedalaman $20 \mathrm{~cm}$ dari permukaan tanah yang diambil dengan cara mencetak tanah menggunakan container kayu untuk mendapatkan kepadatan tanah yang sesuai dengan kondisi nyata di lapangan. Untuk menghindari penguapan yang berlebihan, container harus ditutup rapat dengan menggunakan lembaran plastik. Kemudian tanah dicetak kembali dalam container kaca

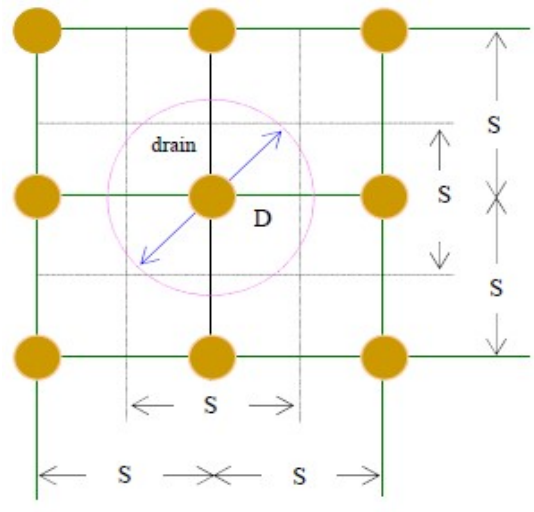

(a). Pola Segiempat berukuran $35 \mathrm{~cm} \times 25 \mathrm{~cm} \times 20 \mathrm{~cm}$ dan ditutup dengan lembaran plastik untuk tujuan yang sama.

Pelaksanaan pengujian dilakukan dalam 2 tahap. Pertama adalah pengujian sifat fisik dan konsolidasi tanah gambut. Kedua adalah pengujian lama waktu pengeringan pada tanah gambut akibat pengaruh metode drainase menggunakan bahan pasir. Kedua tahap pengujian tersebut dilakukan di laboratorium Mekanika Tanah Fakultas Teknik, Universitas Lampung.

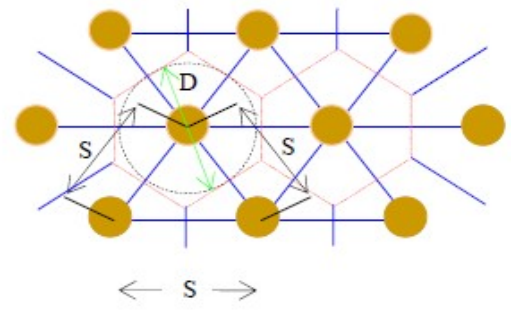

(b). Pola Segitiga

Gambar 1. Pola Vertikal Drain

Diameter lubang sand drain direncanakan sebesar $1,9 \mathrm{~cm}(\mathrm{rw})$ dan R sebesar $5 \mathrm{~cm}$, sehingga nilai $S$ untuk masing-masing pola adalah sebagai berikut :

a. $\quad$ Pola segiempat $=\mathrm{S}=\frac{R}{0,564}=1,773 R$

$$
\mathrm{S}=1,773 \times 5=8,865 \mathrm{~cm} \approx 9 \mathrm{~cm}
$$

b. $\quad$ Pola segitiga $=\mathrm{S}=\frac{R}{0,525}=1,905 R$

$$
\mathrm{S}=1,905 \times 5=9,525 \mathrm{~cm} \approx 9,5 \mathrm{~cm}
$$

Dan beban yang digunakan sebesar $20 \mathrm{~kg}$

Data yang didapatkan dari percobaan diolah, dan kemudian hasil perhitungan tersebut ditabelkan dan dibuat grafik.
Penurunan konsolidasi tanah gambut dengan sumur pasir yang diberikan beban dapat dihitung dengan rumus (Terzaghi, K., Peck, R. B, 1987) : 
St $=U \times S c$

$-(1)$

$U=1-\{(1-U v)(1-U r)\}$

Dengan :

a. Untuk aliran vertikal (Terzaghi, K., Peck, R. B, 1987)

$$
\begin{gathered}
U_{V}=\sqrt{\frac{4 T_{V}}{\pi}} \\
\mathrm{T}_{\mathrm{v}}=\frac{C_{v} \cdot t}{\left(\frac{1}{2} H d r\right)^{2}}
\end{gathered}
$$

$\mathrm{U}=$ derajat konsolidasi rata-rata

Sc = penurunan batas lapisan gambut yang disebabkan oleh konsolidasi primer
Dimana :

$\mathrm{Cv}=$ Koefisien konsolidasi pada arah vertikal $\mathrm{t}=$ lama pengamatan

radial (Terzaghi, K., Peck, R. B, 1987)

$$
\begin{gathered}
U_{r}=1-e^{-\left\{8 T_{r} / F(n)\right\}} \\
T_{r}=\frac{C_{h} t}{4 R^{2}} \\
\mathrm{~F}(\mathrm{n})=\ln (\mathrm{D} / \mathrm{d})-0.75
\end{gathered}
$$

Dimana :

$\mathrm{Ch}=$ Koefisien konsolidasi pada arah radial

$\mathrm{t}=$ lama pengamatan
$\mathrm{Hdr}=$ panjang aliran rata-rata yang harus ditempuh oleh air pori selama proses konsolidasi

\section{b. Untuk aliran}

$\mathrm{R}=$ jari - jari ekivalen

$\mathrm{D}=$ diameter ekivalen

$\mathrm{d}=$ diameter lubang pasir

HASIL DAN PEMBAHASAN

Tabel 1. Hasil Pengujian Sifat Fisik Tanah Gambut (Peat Clay)

\begin{tabular}{|c|l|c|c|}
\hline NO. & \multicolumn{1}{|c|}{ PENGUJIAN } & HASIL UJI & SATUAN \\
\hline 1 & Kadar Air & 218,41 & $\%$ \\
\hline 2 & Berat Volume & 1.10 & $\mathrm{gr} / \mathrm{cm}^{3}$ \\
\hline 3 & Berat Jenis & 1,72 & \\
\hline 4 & Batas-batas Atterberg & & \\
\hline & a. Batas Cair (Liquid Limit) & 137,35 & $\%$ \\
\hline & b. Batas Plastis (Plastic Limit) & 104,86 & $\%$ \\
\hline & c. Indeks Plastisitas (Plasticity Index) & 32,50 & $\%$ \\
\hline & d. Indeks Kecairan (Liquidity Index) & 1 & $\%$ \\
\hline
\end{tabular}

Hasil uji kimia tanah gambut Rawa Sragi Kabupaten Lampung Timur yang dilakukan di Laboratorium Fakultas MIPA Unila. Dapat disimpulkan bahwa tanah gambut yang digunakan dalam penelitian mempunyai komposisi unsur-unsur kimia tanah sebagai berikut:

[160,303\% Organik Tanah

[017,815\% Unsur Magnesium (Mg)

$\square 10,561 \% \quad$ Unsur Kalium (K)
$[05,676 \%$ Unsur Ferrum (Fe)

$\square 01,896 \%$ Unsur Kalsium (Ca)

$\llbracket 3,749 \% \quad$ Unsur - unsur lainnya

\section{Hasil Pengujian Konsolidasi sebelum pembebanan}

Nilai kecepatan waktu konsolidasi diperoleh dari grafik penurunan dengan waktu. Dari grafik ini waktu untuk mencapai konsolidasi $90 \%$ (t90) dapat ditentukan. Nilai- 
Tabel 2. Hasil Perhitungan T90 Tanah Asli

\begin{tabular}{cccccc}
\hline Tegangan $\left(\mathbf{K g} / \mathbf{c m}^{2}\right)$ & $\mathbf{0 , 0 5}$ & $\mathbf{0 , 1}$ & $\mathbf{0 , 2}$ & $\mathbf{0 , 4}$ & $\mathbf{0 , 8}$ \\
\hline \multirow{2}{*}{$T_{90}($ detik) } & 1161.6 & 1685.4 & 1861.494 & 2011.446 & 2018.4 \\
& & & & & \\
\hline
\end{tabular}

Kurva yang dibentuk pada kertas semilogaritma (lampiran) dari hasil percobaan konsolidasi di laboratorium menunjukkan bahwa tanah tersebut struktur tanahnya tidak rusak (Undisturbed), dan terkonsolidasi secara normal (Normaly Consolidated) dengan derajat sensitifitas rendah sampai sedang.

Koefisien konsolidasi $(\mathrm{Cv})$ yang diperoleh dari grafik yang terdapat pada lampiran sebesar 0,0006 cm2/detik berbanding lurus dengan waktu terjadinya konsolidasi. Semakin besar koefisien konsolidasi, maka konsolidasi akan berlangsung semakin cepat.

Nilai indeks tekanan Cc berhubungan dengan penurunan konsolidasi $S$ (semakin kecil Cc maka penurunan konsolidasi semakin kecil). Dari hasil perhitungan : $(C c=e 0-e 1$ / $\log P 1-P 0$ ) diperoleh Cc sebesar 2,4368.

\section{Hasil Uji Vertical Drain dengan Bahan Pasir}

\section{a. Pola Segitiga}

Pengujian ini dilakukan dengan cara melubangi tanah dengan diameter $1,8 \mathrm{~cm}$ yang membentuk pola segitiga, penurunan yang terjadi pada pola segitiga sebesar $2,860 \mathrm{~cm}$ atau $28,6 \mathrm{~mm}$ selama hampir tiga puluh lima hari. Dari hasil perhitungan dengan teori didapatkan penurunan sebesar $0,6444 \mathrm{~cm}$ atau sebesar 6,444 $\mathrm{mm}$. Dibandingkan dengan penurunan dengan menggunakan bahan pasir pada pola segitiga sebesar $2,860 \mathrm{~cm}$, penurunan dengan teori lebih kecil yaitu sebesar 0,6444 cm.

Tabel 3. Hasil Perhitungan T90 Pola Segitiga

\begin{tabular}{llllll}
\hline $\begin{array}{l}\text { Tegangan } \\
\left(\mathbf{K g} / \mathbf{c m}^{2}\right)\end{array}$ & $\mathbf{0 , 0 5}$ & $\mathbf{0 , 1}$ & $\mathbf{0 , 2}$ & $\mathbf{0 , 4}$ & $\mathbf{0 , 8}$ \\
\hline $\mathrm{T}_{90}$ (detik) & 739,84 & 1576,09 & 1780,84 & 2097,64 & 2180,89 \\
\hline
\end{tabular}

Koefisien konsolidasi (Cv) yang diperoleh dari grafik yang terdapat pada lampiran sebesar $0,00079 \mathrm{~cm} 2 /$ menit berbanding lurus dengan waktu terjadinya konsolidasi. Semakin besar koefisien konsolidasi, maka konsolidasi akan berlangsung semakin cepat. Nilai indeks tekanan $\mathrm{Cc}$ berhubungan dengan penurunan konsolidasi $S$ (semakin kecil Cc maka penurunan konsolidasi semakin kecil). Dari hasil perhitungan : $(C c=e 0-e 1 / \log P 1-P 0)$ diperoleh $\mathrm{Cc}$ sebesar 2,5589.

b. Pola Segiempat

Pengujian ini dilakukan dengan cara melubangi tanah dengan diameter $1,8 \mathrm{~cm}$ yang membentuk pola segiempat. Penurunan yang terjadi pada pola segiempat sebesar $3,670 \mathrm{~cm}$ atau $36,70 \mathrm{~mm}$ selama hampir tiga puluh lima hari. Dari hasil perhitungan dengan teori didapatkan penurunan sebesar $0,1197 \mathrm{~cm}$ atau sebesar 1,197 mm. Dibandingkan dengan penurunan dengan menggunakan metode pasir drain yang sebesar $0,369 \mathrm{~cm}$, penurunan dengan teori jauh lebih besar yaitu sebesar $0,1197 \mathrm{~cm}$.

Penurunan tanah selama proses vertikal drain menggunakan bahan pasir pada pola segiempat lebih besar dibandingkan pada penurunan akibat proses vertikal drain menggunakan bahan pasir pada pola segitiga, yaitu sebesar $0,369 \mathrm{~cm}$ pada pola segiempat dan. $0,284 \mathrm{~cm}$ pada pola segitiga. Dari hasil pengujian setelah pembebanan dengan metode sand drain pola segiempat maka didapatkan nilai- nilai hasil grafik konsolidasi seperti pada tabel di bawah ini. 
Tabel 4. Hasil Perhitungan T90 Pola Segiempat

\begin{tabular}{llllll}
\hline Tegangan $\left(\mathbf{K g} / \mathbf{c m}^{2}\right)$ & $\mathbf{0 , 0 5}$ & $\mathbf{0 , 1}$ & $\mathbf{0 , 2}$ & $\mathbf{0 , 4}$ & $\mathbf{0 , 8}$ \\
\hline$T_{90}$ (detik) & 141,61 & 506,25 & 576 & 449,44 & 368,64 \\
\hline
\end{tabular}

Koefisien konsolidasi (Cv) yang diperoleh dari grafik yang terdapat pada lampiran sebesar $0,0028 \mathrm{~cm} 2 /$ menit berbanding lurus dengan waktu terjadinya konsolidasi. Semakin besar koefisien konsolidasi, maka konsolidasi akan berlangsung semakin cepat. Nilai indeks tekanan $\mathrm{Cc}$ berhubungan dengan penurunan konsolidasi $S$ (semakin kecil Cc maka penurunan konsolidasi semakin kecil). Dari hasil perhitungan : $(C c=e 0-e 1 / \log P 1-P 0)$ diperoleh Cc sebesar 1,0041.

Berdasarkan hasil perhitungan nilai penurunan tanah pola segitiga dan pola segiempat secara teori maka perbedaan kedua pola tersebut dapat dilihat pada grafik di bawah ini.

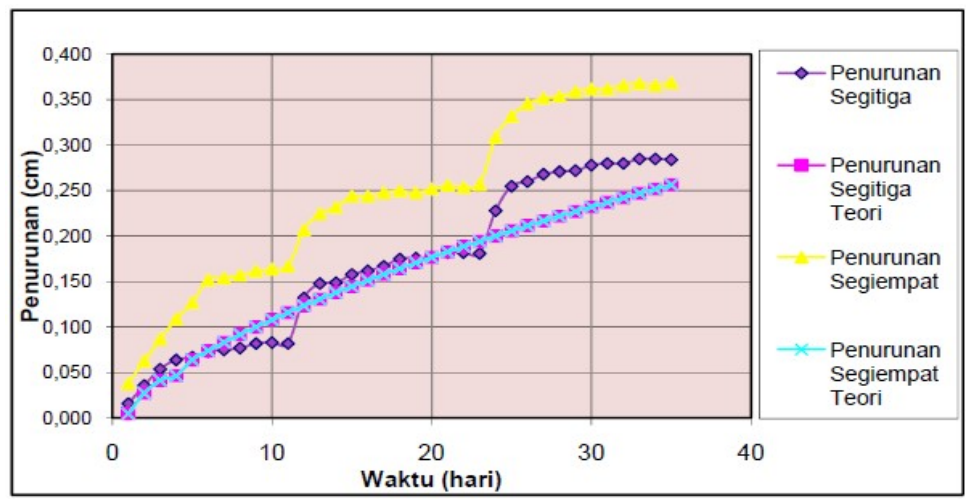

Gambar 2 Grafik perbandingan penurunan tanah pada pola segitiga dan pola segiempat hasil pengamatan dengan hitungan teori.

Perbedaan antara pola segitiga dan pola segiempat dalam hal pengaliran air dan lama waktu yang diperlukan untuk pengaliran dapat dilihat pada gambar berikut.

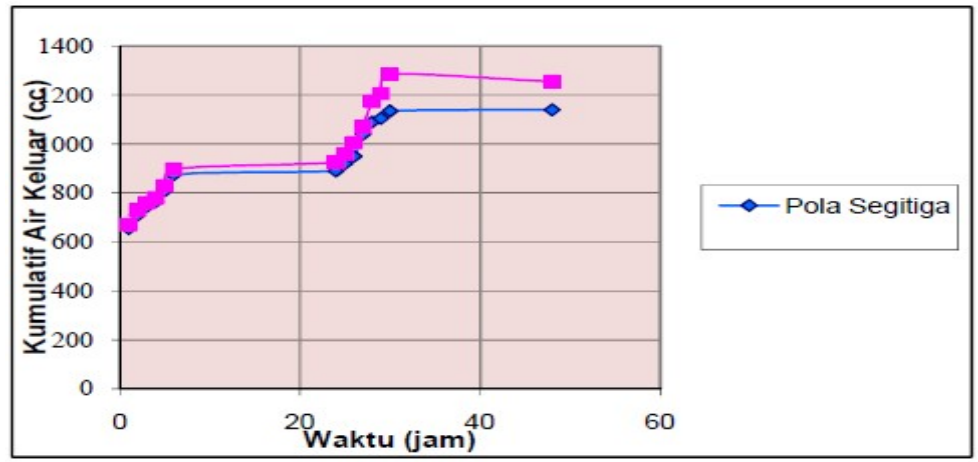

Gambar 3. Grafik perbandingan kumulatif air keluar terhadap waktu pada pengujian pengaliran air pada tanah lempung dengan metode sand drain dengan pola segitiga dan pola segiempat 


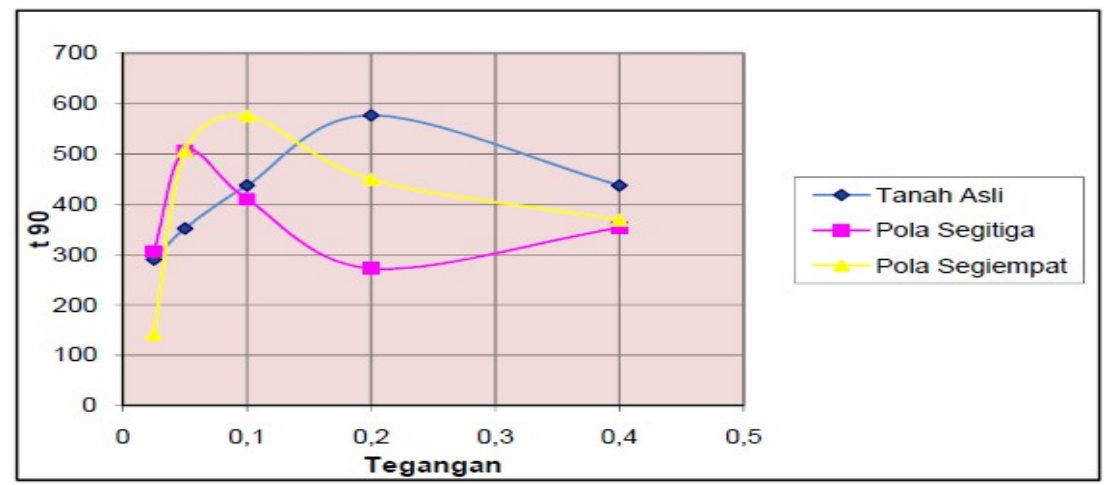

Gambar 4. Grafik Perbandingan T90

Berdasarkan hasil uji sifat fisiknya, tanah termasuk dalam kategori tanah peat humus karena mempunyai kadar serat sebesar 4,92 $\%$, berdasarkan standar ASTM tanah gambut yang memiliki kadar serat $<33,3 \%$ termasuk tanah gambut peat humus, dan berdasarkan kandungan abunya tanah ini tergolong medium ash karena mempunyai kadar abu sebesar $44,84 \%$. Berdasarkan percobaan di Laboratorium dengan menggunakan model tanah yang berukuran $35 \times 25 \times 20 \mathrm{~cm}$ yang diberi drain-drain pasir (sand drain) yang membentuk pola dengan pembebanan bertahap, didapatkan penurunan tanah sebesar $0,369 \mathrm{~cm}$ dengan pola segiempat selama selang waktu 35 hari dan penurunan tanah sebesar $0,284 \mathrm{~cm}$ untuk pola segitiga selama selang waktu 35 hari.

Berdasarkan hasil uji pengaliran air pola segitiga mampu mengalirkan air sebesar 1255 cc selama selang waktu 48 jam, dan 1140 cc selama selang waktu 48 jam pada pola segiempat. Hal ini disebabkan karena pada pola segiempat memiliki drain yang lebih banyak (9 drain) dibanding dengan pola segitiga (7 drain) yang memungkinkan untuk mengalirkan air lebih banyak dan dalam waktu yang singkat, ini membuktikan bahwa metode sand drain dapat membantu mempercepat pengaliran air pada tanah gambut yang memiliki kemampuan mengalirkan air yang kurang baik. Air yang mengalir tidak seluruhnya ke arah horizontal tetapi juga kearah vertikal yaitu kearah pasir. Sebagian air yang menuju arah vertikal diserap oleh pasir dan yang arah horizontal keluar melalui pipa

\section{KESIMPULAN}

1. Tanah gambut yang digunakan sebagai sampel penelitian berasal dari Desa Rawa Sragi, Lampung Tengah, termasuk dalam kategori tanah gambut peat humus, karena berdasarkan nilai kadar serat yang kurang dari $33,3 \%$. Dan termasuk jenis tanah gambut medium ash, karena berdasarkan kandungan abu sebesar $44,84 \%$. Berdasarkan klasifikasi tanah menurut AASHTO tanah ini tergolong dalam kelompok A-7-6, dengan tingkatan tanah buruk.

2. Penggunaan metode sand drain dengan pola segiempat ternyata dapat menurunkan tanah lebih cepat daripada dengan pola segitiga. Hal ini disebabkan karena lubang pada pola segiempat lebih banyak (9 lubang) dibandingkan pola segitiga (7 lubang).

3. Metode sand drain sangat berpengaruh besar terhadap percepatan penurunan tanah yang diuji, karena drain-drain yang dibuat berfungsi untuk memperpendek lintasan air pori kearah horizontal sehingga air cepat keluar dari dalam tanah.

4. Nilai Cv (koefisien konsolidasi) sebelum pembebanan lebih besar daripada setelah pembebanan, sedangkan nilai Cc (indeks pemampatan) sesudah pembebanan lebih besar daripada sebelum pembebanan. Hal ini dapat terjadi karena nilai penurunan tanah sebelum pembebanan lebih besar daripada nilai penurunan tanah setelah pembebanan.

\section{DAFTAR PUSTAKA}

Bowles, J. E. 1989. Sifat-sifat Fisis dan Geoteknis Tanah. Erlangga. Jakarta.

Das, B. M. 1993. Mekanika Tanah. (Prinsip prinsip Rekayasa Geoteknis). Jilid I Penerbit Erlangga, Jakarta. 
Day, J.M. 1979. Associative symbioses in dinitrogen fixing sites. InW.E.Newton, and C.J. Nyman. Proc. 1st Int. Symp. Nitrogen Fixation. Washington State University Press

Dunn, I. S., Anderso, I. R. And Kiefer, F. W. 1992. Dasar - dasar Analisis Geoteknis. IKIP Semarang Pers, Semarang.

Hardiatmo, H. C. 1992. Mekanika Tanah. Gramedia Pustaka Umum. Jilid I Jakarta.

Pemukiman dan Prasarana Wilayah Republik Indonesia, Departemen. 2001. Pedoman Konstruksi Jalan Di Atas Tanah Gambut dan Organik. CUR. Indonesia.
Terzaghi, K., Peck, R. B. 1987. Mekanika Tanah Dalam Praktek Rekayasa. Penerbit Erlangga, Jakarta.

Zainorabidin, A. And Bakar, I. 2003. Engineering properties of in-situ and modified hemic peat soil in Western Johore. In International Conference on Advances in Soft Soil Engineering and Technology, ed. Huat et al, 173-182. Putra Jaya. Malaysia

Razali, Siti. Bakar, I and Zainorabidin, A. 2012. Behaviour of Peat Soil in Instrumented Physical Model Studies. Journal of Procedia Engineering 53 ( 2013 ) 145 155. 